\title{
Initial circulatory response to active standing in Parkinson's disease without typical orthostatic hypotension
}

\author{
Resposta circulatória inicial após ortostatismo ativo na doença de Parkinson sem \\ hipotensão ortostática típica
}

Guillermo Delgado', Bruno Estañol', Mayela Rodríguez-Violante², Jesús Antonio González-Hermosillo ${ }^{3}$, Óscar Infante-Vázquez ${ }^{4}$

\begin{abstract}
While the circulatory response to orthostatic stress has been already evaluated in Parkinson's disease patients without typical orthostatic hypotension (PD-TOH), there is an initial response to the upright position which is uniquely associated with active standing (AS). We sought to assess this response and to compare it to that seen in young healthy controls (YHC). Method: In 10 PD-TOH patients (8 males, $60 \pm 7$ years, Hoehn and Yahr $\leq 3$ ) the changes in systolic blood pressure (SBP) and heart rate that occur in the first 30 seconds (sec) of standing were examined. Both parameters were non-invasively and continuously monitored using the volume-clamp method by Peñáz and the Physiocal criteria by Wesseling. The choice of sample points was prompted by the results of previous studies. These sample points were compared to those of $10 \mathrm{YHC}$ ( 8 males, $32 \pm 8$ years). Results: The main finding of the present investigation was an increased time between the AS onset and SBP overshoot in PD-TOH group ( $24 \pm 4$ vs. $19 \pm 3 \mathrm{sec} ; \mathrm{p}<0.05)$. Conclusion: This delay might reflect a prolonged latency in the baroreflex-mediated vascular resistance response, but more studies are needed to confirm this preliminary hypothesis.
\end{abstract}

Keywords: Parkinson's disease, autonomic nervous system, orthostatic hypotension, hemodynamics, cardiovascular physiological Phenomena.

\section{RESUMO}

Apesar da resposta circulatória ao estresse ortostático já foi estudada em pacientes com doença de Parkinson sem hipotensão ortostática típica (PD-TOH), não há uma resposta inicial que é exclusivamente associada com o ortostase ativa (AS). Portanto, buscou-se avaliar esta

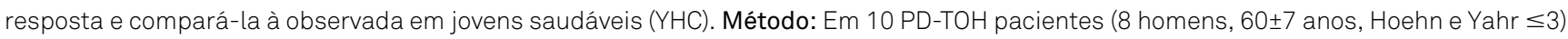
as mudanças na pressão arterial sistólica (PAS) e da frequência cardíaca que ocorrem nos primeiros 30 segundos (seg) de pé foram examinados. Ambos parâmetros foram monitorizados continuamente através do método Penõáz e os critérios de Wesseling. Os pontos de amostragem foram escolhidos com base em estudos anteriores. Estes pontos foram comparados com os de $10 \mathrm{YHC}$ ( $32 \pm 8$ anos). Resultados: 0 principal achado deste estudo foi o aumento do tempo entre o início de AS e rebote sistólica no grupo PD-TOH (24 4 vs $19 \pm 3$ seg, $p<0,05)$. Conclusão: Este atraso pode refletir uma latência prolongada na resposta da resistência vascular mediado pelo barorreflexo, mas outros estudos são necessários para confirmar esta hipótese preliminar.

Palavras-chave: doença de Parkinson, sistema nervoso autônomo, hipotensão ortostática, hemodinâmica, fenômenos fisiológicos cardiovasculares.

There is an initial circulatory or hemodynamic response (first 30 seconds) to the upright position which is solely associated with active standing (AS) ${ }^{1}$. This response has been described in both young and elderly healthy subjects ${ }^{1-4}$. When orthostatic hypotension occurs within 15 seconds (sec) of standing, it is termed initial orthostatic hypotension

\footnotetext{
${ }^{1}$ Laboratory of Clinical Neurophysiology, Department of Neurology and Psychiatry, National Institute of Medical Sciences and Nutrition Salvador Zubirán; ${ }^{2}$ Movement Disorders Clinic, National Institute of Neurology and Neurosurgery Manuel Velasco Suárez;

${ }^{3}$ Department of Electrocardiography and Electrophysiology, National Institute of Cardiology Ignacio Chávez;

${ }^{4}$ Department of Electromechanical Instrumentation, National Institute of Cardiology Ignacio Chávez.

Correspondence: Guillermo Delgado; Laboratory of Clinical Neurophysiology, Department of Neurology and Psychiatry, National Institute of Medical Sciences and Nutrition Salvador Zubirán (INNSZ); Vasco de Quiroga 15, Tlalpan; C.P. 14000; México D.F. - México; E-mail: grdelgadog@gmail.com, guillermo.delgadogr@uanl.edu.mx

Conflict of interest: There is no conflict of interest to declare.

Received 01 April 2013; Received in final form 14 October 2013; Accepted 11 November 2013.
} 
(IOH) and is attributed to a mismatch between cardiac output and peripheral vascular resistance (PVR) ${ }^{1}$. The aforesaid mismatch is due to a reduction in PVR and moreover, this decrease is clearly associated with the depth of the blood pressure (BP) drop ${ }^{1}$. Symptoms of cerebral hypoperfusion are likewise present during this drop ${ }^{1}$.

Orthostatic symptoms (OS) occur when cerebral perfusion is sufficiently impaired and, in turn, hypoperfusion develops when cerebrovascular autoregulation (CVA) fails to cope with the BP reduction ${ }^{5,6}$. This is why, in typical orthostatic hypotension ( $\mathrm{TOH})$, these symptoms takes place more readily in patients with severe cerebrovascular autoregulatory failure ${ }^{5}$. Nevertheless, autonomic dysfunction in Parkinson's disease (PD) does not seem to impair the CVA nor its response to orthostatic stress ${ }^{6,7}$. These CVA differences could account for the reduced reporting of OS in $\mathrm{PD}^{6}$.

Autonomic dysfunction in PD is associated with a generalized sympathetic denervation ${ }^{8}$. Recently, it has been reported that $\mathrm{PD}$ patients with $\mathrm{TOH}(\mathrm{PD}+\mathrm{TOH})$ have a lower basal leg vascular resistance, which might suggest that sympathetic denervation is more pronounced in $\mathrm{PD}+\mathrm{TOH}$ than in PD patients without TOH (PD-TOH) ${ }^{8}$. Yet, Oka et al. documented that latent cardiac and vasomotor sympathetic dysfunction occurs in PD-TOH patients ${ }^{9}$.

While the hemodynamic response to orthostatic stress has been already evaluated in $\mathrm{PD}-\mathrm{TOH}^{8}$, IOH can be documented only by continuous beat-to-beat BP monitoring during $\mathrm{AS}^{1}$. Consequently, in this study, we assessed beat-tobeat the initial hemodynamic response to AS in $\mathrm{PD}-\mathrm{TOH}$ and compared this response to that seen in young healthy controls (YHC).

\section{METHOD}

\section{Study population}

We enrolled 20 non-institutionalized patients with mild to moderate PD (16 males, mean age $60 \pm 7$ years, mean duration of disease $3.5 \pm 2$ years, Hoehn and Yahr stage $2[1-3])^{10}$. All of them fulfilled the UK Brain Bank Clinical Criteria for $\mathrm{PD}^{11}$. PD+TOH patients were excluded from the present study; the foregoing condition was defined as a fall in BP of at least $20 \mathrm{mmHg}$ systolic (SBP) and $10 \mathrm{mmHg}$ diastolic (DBP) within 3 minutes (min) in the upright position ${ }^{12,13}$. BP measurement was performed using standard sphygmomanometry. These patients were all investigated after 12 hours off medication. We also included ten YHC (8 males, mean age $32 \pm 8$ years) as control group, since the transient hypotension seen during AS does not increase with age ${ }^{1}$. Their health status was determined by a thoughtful medical history and a directed physical examination. This study was approved by the Ethical Committee of the National Institute of Medical Sciences and Nutrition and an informed written consent was obtained from all participants.

\section{Protocol}

All evaluations were performed in the morning. Participants in both groups were instructed to avoid alcohol, caffeinated beverages and over-the-counter medications after 22:00 on the night before the evaluation. Finger arterial pressure (FAP) was non-invasively and continuously (beatto-beat) monitored using the volume-clamp method by Penõáz and the Physiocal (physiological calibration) criteria by Wesseling ${ }^{14}$. SBP, DBP and mean BP (MBP) were then reconstructed from FAP; and heart rate (HR) was meanwhile computed as the inverse of the interbeat interval (Finometer $^{\circledR} \quad$ PRO, Finapres Medical Systems, Amsterdam $)^{14}$. Measurements were made at supine rest before AS (5 min), during AS, and at the upright position after AS (5 min). Participants were not specifically instructed to stand up quickly. Hemodynamic parameters were extracted with BeatScope for Windows ${ }^{\mathrm{B}}$ (v.1.1a, Finapres Medical Systems).

\section{Data analysis and statistics}

This investigation was focused on SBP and HR changes in the initial hemodynamic response to AS and was carried out utilizing BeatScope software. Supine values of SBP and HR were calculated as the corresponding arithmetic means of the 5 min supine rest, and afterwards SBP response was determined at time $(t)=-10 \mathrm{sec},-5 \mathrm{sec}, 0 \mathrm{sec}$, time at peak $\mathrm{SBP}_{\mathrm{a}}\left(t_{\mathrm{SBPa}}\right)$, time at valley $\mathrm{SBP}_{\mathrm{b}}\left(t_{\mathrm{SBPb}}\right)$, time at $\mathrm{SBP}$ overshoot $\left(t_{\mathrm{SBPos}}\right)$ and $+30 \mathrm{sec}$. HR response was concurrently measured at $t=-10 \mathrm{sec},-5 \mathrm{sec}, 0 \mathrm{sec}$, time at peak $\mathrm{HR}_{\mathrm{a}}$ $\left(t_{\mathrm{HRa}}\right)$, time at valley $\mathrm{HR}_{\mathrm{b}}\left(t_{\mathrm{HRb}}\right)$, time at peak $\mathrm{HR}_{\mathrm{c}}\left(t_{\mathrm{HRc}}\right)$, time at valley $\mathrm{HR}_{\mathrm{d}}\left(t_{\mathrm{HRd}}\right)$ and $+30 \mathrm{sec}$. $t_{0}$ was defined as the start of AS. The selection of sample points was prompted by the results of previous studies ${ }^{2,3,15,16}$. Unless otherwise stated, hemodynamic data are reported as absolute values and as changes between two different sample points $(\Delta)$. When possible, vasoconstrictor (VCI) and baroreflex sensitivity (BRI) indices, as advanced by Yamaguchi et al., were additionally calculated ${ }^{16}$. Baroreflex sensitivity (BRS) was also obtained using a slightly modified version of the method already employed by Imholz et al. ${ }^{15}$ Statistical analysis was performed with STATISTICA for Windows ${ }^{\circledR}$ (v.5.1). Prior to group analyses, individual data were tested for normality (Shapiro-Wilk test). Comparisons between groups were performed by either using Student's t-test or Mann-Whitney U test. A p-value below $0.05(\mathrm{p}<0.05)$ was considered significant. All results are expressed as mean \pm SD or median (interquartile range). 


\section{RESULTS}

All data were visually inspected prior to analysis. Five patients were excluded either because of tremor-induced artifact $(n=2)$ or asymptomatic TOH $(n=3)$. Besides, the characteristic hemodynamic pattern seen during AS was almost completely lost in five patients ${ }^{1-3,17}$, thus hampering attempts to locate the sample points and further comparison between groups. Data from these patients were hence eliminated from study analysis $(n=5)$.

Initial hemodynamic response (Tables 1 and 2). In the ten remaining patients ( 8 males, mean age $60 \pm 7$ years), basal SBP and HR were, respectively, $99 \pm 8$ millimetres of mercury $(\mathrm{mmHg})$ and $64 \pm 8$ beats per min (bpm). On standing SBP increased suddenly from $107 \pm 10\left(t_{0}\right)$ to $133 \pm 18 \mathrm{mmHg}$ $\left(\mathrm{SBP}_{\mathrm{a}}\right)$ and then decreased from that value to $75 \pm 20 \mathrm{mmHg}$ $\left(\mathrm{SBP}_{\mathrm{b}}\right)$. An overshoot was evident in seven patients during the recovery phase of $\mathrm{SBP}\left(\mathrm{SBP}_{\mathrm{os}}, 127 \pm 18 \mathrm{mmHg}\right)$. These changes reached its maximum $\left(\mathrm{SBP}_{\mathrm{a}}\right)$ after $3 \pm 1$ sec $\left(t_{\mathrm{SBPa}}\right)$ and its minimum $\left(\mathrm{SBP}_{\mathrm{b}}\right)$ after $11 \pm 2 \mathrm{sec}\left(t_{\mathrm{SBPb}}\right)$. For its part, in the seven aforementioned patients, $\mathrm{SBP}_{\mathrm{os}}$ was reached after $24 \pm 4 \sec \left(t_{\mathrm{SBPos}}\right)$. Thereafter, at the end of the initial hemodynamic response $\left(t_{+30}\right), \mathrm{SBP}$ was $113 \pm 23 \mathrm{mmHg}$ (Figure 1).

Standing was accompanied by an absence of a true $\mathrm{HR}_{\mathrm{a}}$ in all patients and, as a consequence, also by an absence of $\mathrm{HR}_{\mathrm{b}}$. The awaited transition from the HR surge to an increscent further rise was likewise not precisely definable. In this manner, HR increased gradually from $66 \pm 7\left(t_{0}\right)$ to $89 \pm 8 \mathrm{bpm}\left(\mathrm{HR}_{\mathrm{c}}\right)$ upon standing and subsequently dropped from that value to $70 \pm 6\left(\mathrm{HR}_{\mathrm{d}}\right)$. These changes reached its

Table 1. Initial HR response to active standing.

\begin{tabular}{|c|c|c|}
\hline & PD-TOH $(n=10)$ & $\mathrm{YHC}(n=10)$ \\
\hline $\mathrm{MHR}_{\mathrm{SR}}(\mathrm{bpm})$ & $64 \pm 8$ & $63 \pm 7$ \\
\hline $\mathrm{HR}_{-10}$ & $64 \pm 8$ & $61 \pm 5$ \\
\hline $\mathrm{HR}_{-5}$ & $64 \pm 9$ & $63 \pm 6$ \\
\hline $\mathrm{HR}_{0}$ & $66 \pm 7$ & $65 \pm 6$ \\
\hline $\mathrm{HR}_{\mathrm{a}}$ & - & $86 \pm 5^{+}$ \\
\hline $\mathrm{HR}_{\mathrm{b}}$ & - & $80 \pm 9^{\ddagger}$ \\
\hline$H R_{c}$ & $89 \pm 8 *$ & $103 \pm 11$ \\
\hline$H R_{d}$ & $70 \pm 6$ & $69 \pm 7$ \\
\hline $\mathrm{HR}_{+30}$ & $72 \pm 8$ & $73 \pm 9$ \\
\hline$t_{\mathrm{HRa}}(\mathrm{sec})$ & - & $2 \pm 1^{\dagger}$ \\
\hline$t_{\mathrm{HRb}}$ & - & $4 \pm 1^{\ddagger}$ \\
\hline$t_{\mathrm{HRc}}$ & $13 \pm 4$ & $12 \pm 3$ \\
\hline$t_{\mathrm{HRd}}$ & $23 \pm 5$ & $20 \pm 2$ \\
\hline
\end{tabular}

All results are expressed as meantstandard deviation. PD-TOH: Parkinson's disease without typical orthostatic hypotension; YHC: young healthy controls; $\mathrm{MHR}_{\mathrm{SR}}$ : mean heart rate (HR) during a 5-min supine rest; bpm: Beats per minute; $\mathrm{HR}_{-10}$ : HR at 10 seconds (sec) before active standing (AS); $\mathrm{HR}_{-5}$ : HR at 5 sec before AS; $H_{R}$ : HR at the start of AS; $H_{\mathrm{a}}$ : HR at first peak; $H R_{\mathrm{b}}$ : HR at first valley; $H_{\mathrm{c}}$ : HR at second peak or maximum; $\mathrm{HR}_{d}$ : $\mathrm{HR}$ at second valley; $\mathrm{HR}_{+30}$ : $\mathrm{HR}$ at $30 \mathrm{sec}$ after $\mathrm{AS}$; $t_{\mathrm{HRa}}$ : Time at $\mathrm{HR}_{a} ; t_{\mathrm{HRb}}$ : Time at $\mathrm{HR}_{\mathrm{b}}$; $t_{\mathrm{HRc}}$ : Time at $\mathrm{HR}_{\mathrm{c}}$; $t_{\mathrm{HRd}}$ : Time at $\mathrm{HR}_{\mathrm{d}}$. ${ }^{\star} p<0.05$ PD-TOH vs. YHC. ${ }^{+} n=9 .{ }^{*} n=7$. maximum $\left(\mathrm{HR}_{\mathrm{c}}\right)$ after $13 \pm 4 \mathrm{sec}\left(t_{\mathrm{HRc}}\right)$ and its minimum $\left(\mathrm{HR}_{\mathrm{d}}\right)$ after $23 \pm 5 \mathrm{sec}\left(t_{\mathrm{HRd}}\right)$. HR was lastly $72 \pm 8 \mathrm{bpm}$ at $t_{+30}$ (Figure 1).

Patients were slower to stand up than YHC (11.7 [8.8-14] vs. 4.9 [4.2-5] sec; $\mathrm{p}<0.001) . \mathrm{SBP}_{\mathrm{os}}$ was evident in nine $\mathrm{YHC}$ during the recovery phase of SBP $(115 \pm 10 \mathrm{mmHg})$. While its value in $\mathrm{mmHg}$ was not significantly different between groups, its timing $\left(t_{\mathrm{SBPos}}\right)$ was delayed in the PD-TOH group $(24 \pm 4$ vs. $19 \pm 3$ sec; $\mathrm{p}<0.05)$. The remaining SBP parameters did not significantly differ from those found in YHC (Figures 1 and 2). $\mathrm{HR}_{\mathrm{a}}$ (or its corresponding aforedescribed transition) was present in nine YHC $(86 \pm 5 \mathrm{bpm})$ at $2 \pm 1 \mathrm{sec}\left(t_{\mathrm{HRa}}\right) ; \mathrm{HR}_{\mathrm{b}}$ was afterwards identified in only seven YHC $(80 \pm 9 b p m)$ at $4 \pm 1 \mathrm{sec}\left(t_{\mathrm{HRb}}\right) . \mathrm{HR}_{\mathrm{c}}$ was smaller in the $\mathrm{PD}-\mathrm{TOH}$ group than in $\mathrm{YHC}(89 \pm 8$ vs. $103 \pm 11 \mathrm{bpm}$; $\mathrm{p}<0.05)$, howbeit its timing $\left(t_{\mathrm{HRc}}\right)$ did not significantly differ between groups. No significant differences were found between groups for the rest of the HR parameters (Figures 1 and 2).

Baroreflex and vasoconstriction (Table 3). BRI and VCI were determined in seven patients and in almost all YHC $(n=9)$. BRI was lower in PD-TOH than in YHC. VCI was also decreased, although not significantly $(p=0.09)$, in the former group (Figure 3). BRS was measured in all the participants and did not significantly differ between groups.

BP abnormalities. Three patients and six YHC met the criteria for asymptomatic $\mathrm{IOH}^{1}$. In one patient, SBP recovery phase was noticeably prolonged $(28 \mathrm{sec}$ ) but nevertheless it does not fulfilled the TOH criteria, since BP after standing for 3 min was not altered ${ }^{1}$. This matter will be addressed in detail in a subsequent communication.

Table 2. Initial SBP response to active standing.

\begin{tabular}{|c|c|c|}
\hline & PD-TOH $(n=10)$ & $\mathrm{YHC}(\mathrm{n}=10)$ \\
\hline $\operatorname{MSBP}_{\mathrm{SR}}(\mathrm{mmHg})$ & $99 \pm 8$ & $100 \pm 9$ \\
\hline $\mathrm{SBP}_{-10}$ & $108 \pm 7$ & $102 \pm 9$ \\
\hline $\mathrm{SBP}_{-5}$ & $107 \pm 8$ & $102 \pm 9$ \\
\hline $\mathrm{SBP}_{0}$ & $107 \pm 10$ & $102 \pm 7$ \\
\hline $\mathrm{SBP}_{\mathrm{a}}$ & $133 \pm 18$ & $123 \pm 17$ \\
\hline $\mathrm{SBP}_{b}$ & $75 \pm 20$ & $70 \pm 16$ \\
\hline SBPos $_{\text {os }}$ & $127 \pm 18^{\dagger}$ & $115 \pm 10^{\ddagger}$ \\
\hline $\mathrm{SBP}_{+30}$ & $113 \pm 23$ & $108 \pm 15$ \\
\hline $\boldsymbol{\Delta}_{\mathrm{SBPO}-\mathrm{SBPb}}(\mathrm{mmHg})$ & $31 \pm 17$ & $31 \pm 13$ \\
\hline$t_{\mathrm{SBPa}}(\mathrm{sec})$ & $3 \pm 1$ & $2 \pm 0.8$ \\
\hline$t_{\mathrm{SBPb}}$ & $11 \pm 2$ & $10 \pm 1$ \\
\hline$t_{\text {SBPos }}$ & $24 \pm 4^{t \star}$ & $19 \pm 3^{\ddagger}$ \\
\hline \multicolumn{3}{|c|}{ 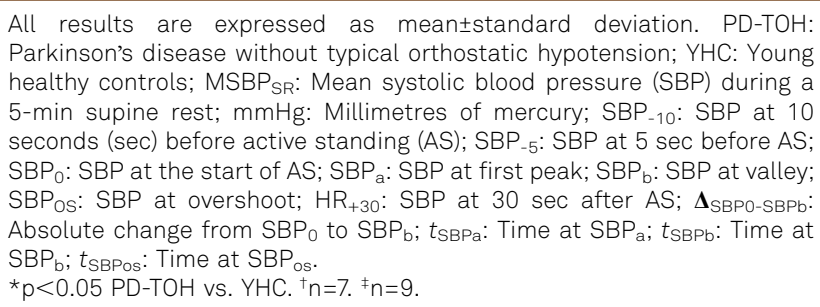 } \\
\hline
\end{tabular}


A

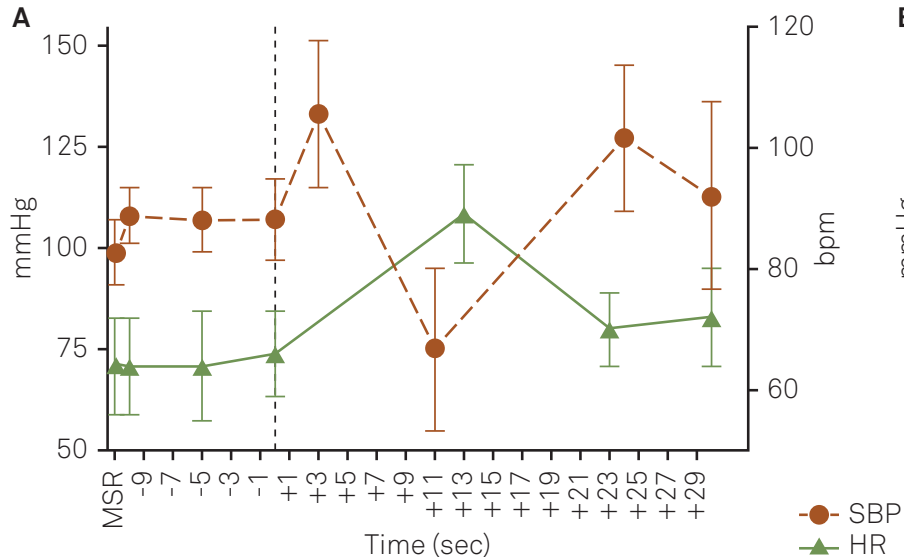

B

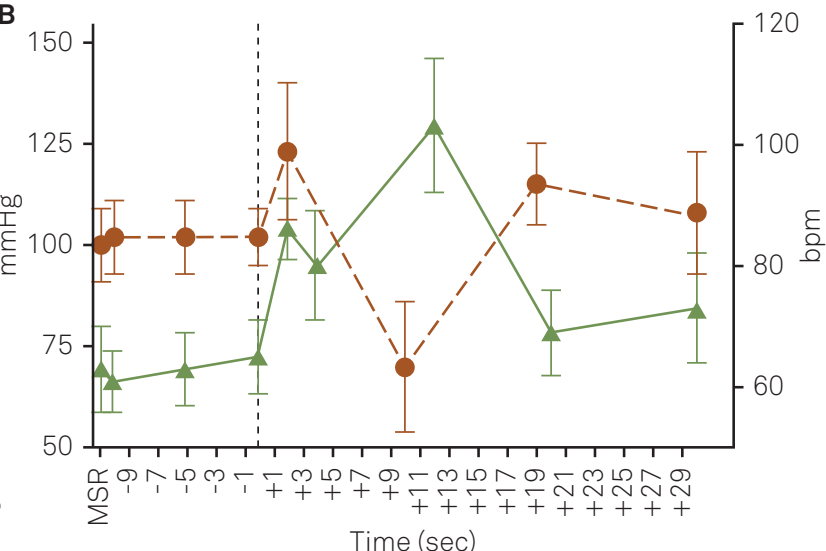

Figure 1. Initial hemodynamic response in PD-TOH. The vertical dashed line indicates $t_{0}$, i.e., the AS onset (A). Initial hemodynamic response in YHC (B); mmHg: millimetres of mercury; bpm: beats per minute; MSR: mean value (SBP or HR) during a 5-min supine rest; sec: seconds; SBP: systolic blood pressure; HR: heart rate; PD-TOH: Parkinson's disease without typical orthostatic hypotension; AS: active standing; YHC: young healthy controls.

A

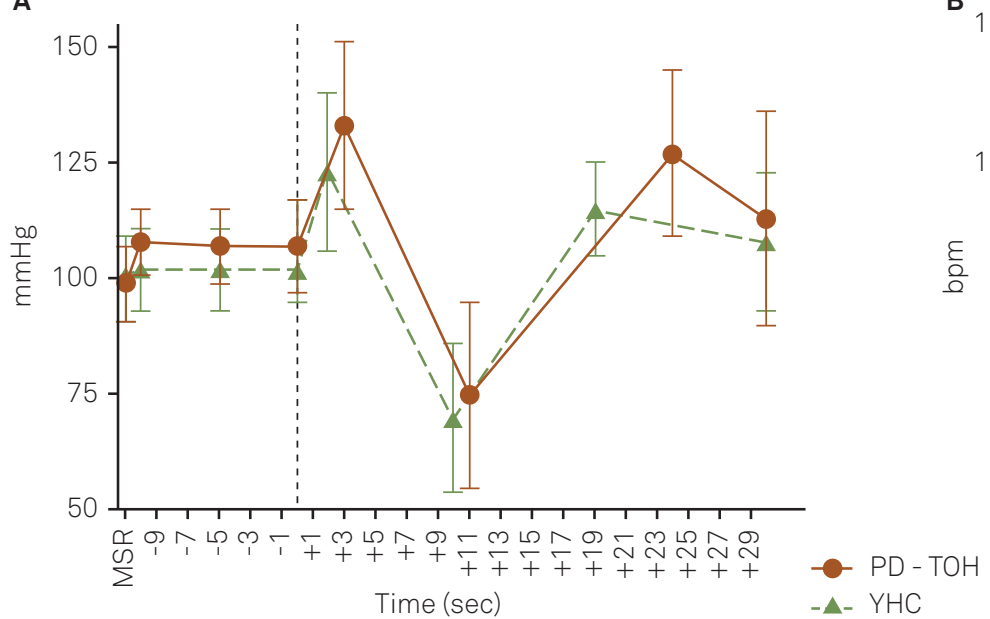

B

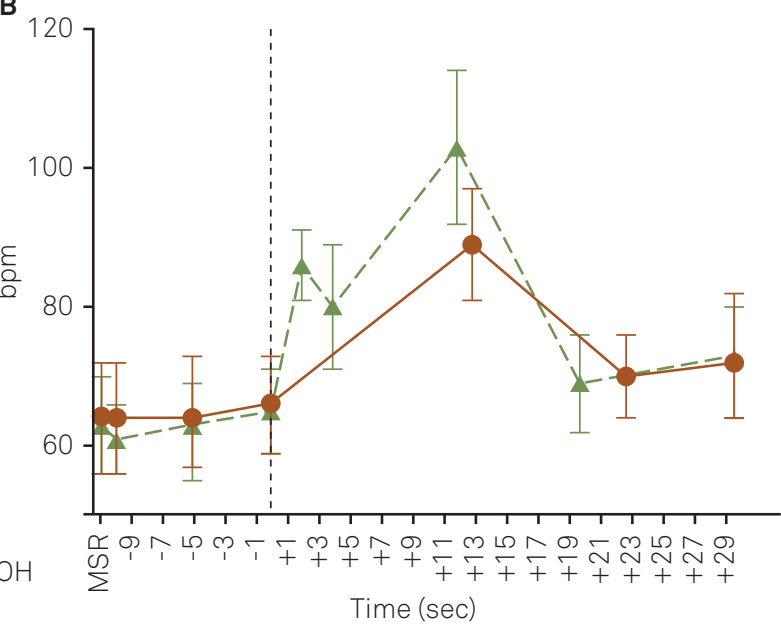

Figure 2. Comparison of the initial SBP response between PD-TOH (solid line) and YHC (dashed line). The vertical dashed line indicates $t_{0}$, i.e., the AS onset (A). Comparison of the initial HR response between PD-TOH (solid line) and YHC (dashed line). Note that the bimodal pattern of this response is entirely lost in PD-TOH (B); mmHg: millimetres of mercury; bpm: beats per minute; MSR: mean value (SBP or HR) during a 5-min supine rest; sec: seconds; PD-TOH: Parkinson's disease without typical orthostatic hypotension; YHC: young healthy controls; SBP: systolic blood pressure; AS: active standing; HR: heart rate.

\section{DISCUSSION}

The main finding of the present investigation was an increased time $\left(t_{\mathrm{SBP} o \mathrm{~s}}\right)$ between the start of $\mathrm{AS}\left(t_{0}\right)$ and the

Table 3. Baroreflex and vasoconstriction.

\begin{tabular}{lcc}
\hline & PD-TOH $(n=10)$ & YHC $(n=10)$ \\
\hline $\mathrm{VCl}(\mathrm{mmHg} / \mathrm{sec})$ & $2.9+1.2^{\dagger}$ & $4.0+1.4^{\ddagger}$ \\
$\mathrm{BRI}(\mathrm{bpm} / \mathrm{mmHg})$ & $0.6+0.5^{\dagger \star}$ & $2.2+1.0^{\ddagger}$ \\
$\mathrm{BRS}(\mathrm{msec} / \mathrm{mmHg})$ & $9.1(5.4-10.8)$ & $9.9(8.5-16.6)$ \\
\hline
\end{tabular}

All results are expressed as mean \pm standard deviation or median (interquartile range). PD-TOH: Parkinson disease without typical orthostatic hypotension; YHC: Young healthy controls; VCl: Vasoconstrictor index; BRI: Baroreflex sensitivity index as calculated by Yamaguchi et al. ${ }^{14}$; BRS: Baroreflex sensitivity as computed by Imholz et al.13; $\mathrm{mmHg}$ : Millimetres of mercury; sec: Second; bpm: Beats per minute; msec: Millisecond.

${ }^{\star} p<0.01$ PD-TOH vs. YHC. ${ }^{+} n=7 .{ }^{\ddagger} n=9$. overshoot $\left(\mathrm{SBP}_{\mathrm{os}}\right)$ in $\mathrm{PD}-\mathrm{TOH}$ group. When compared between groups, SBP (in $\mathrm{mmHg}$ ) was not significantly different at $t_{\mathrm{SBP} \text {; }}$; notwithstanding it could not be determined in three patients. Peripheral sympathetic vasoconstriction, in part baroreflex-mediated, is responsible for the rebound of $\mathrm{BP}$ from $\mathrm{SBP}_{\mathrm{b}}$ to $\mathrm{SBP}_{\text {os }}$ following $\mathrm{AS}^{1,18}$. Local reflexes are involved as well in this PVR increment ${ }^{8,19,20}$. Except for the venoarteriolar response (VAR) in those aged over 75 years, both central and local responses are independent of age in healthy subjects ${ }^{1,19,21}$. Thus, we suggest that an increased $t_{\mathrm{SBP} \text { s }}$ may be caused either by an impaired VAR or by an abnormal baroreflex response. Indeed, these mechanisms are not mutually exclusive ${ }^{22}$.

With respect to the first possibility, Andersen et al. found that, in PD patients without symptoms or signs of autonomic dysfunction, local reflexes did not differ from those 


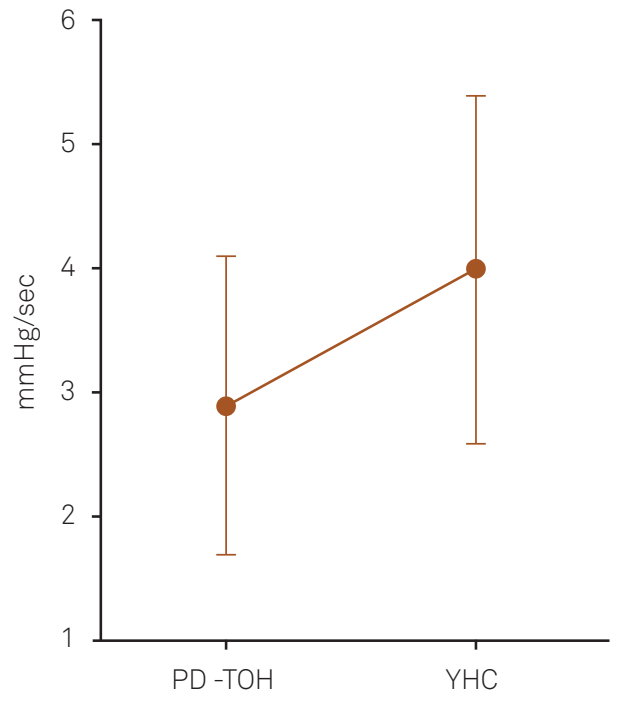

Figure 3. Vasoconstrictor index is comparatively lower in PD$\mathrm{TOH}$, although not significantly $(p=0.09)$. This lack of significant difference may be due to the way in which it is calculated; mmHg: millimetres of mercury; sec: seconds; PD-TOH: Parkinson's disease without orthostatic hypotension.

in age-matched healthy controls ${ }^{19}$. This finding was corroborated by Fusina et al. ${ }^{23}$ and more recently by Groothuis et $a .^{8}$ Regarding the second possibility, it is noteworthy that baroreflex function assessment has concentrated on baroreceptor-HR reflex, even though PVR control is of greater importance during orthostatic stress. In the same manner, this attention has focused on the sensitivity of the baroreflex response and not in its latency. Gulli et al. reported, in connection with the foregoing, a prolonged delay in the baroreflex-mediated PVR response, after baroreceptor unloading (simulation of BP drop), in patients with poor orthostatic tolerance $^{24}$. Additionally, it must be noted that the temporal response to baroreceptor unloading is similar in young and older healthy subjects ${ }^{25}$. We therefore deemed the latter possibility as more likely in the present case.

VCI was proposed as an indicator of PVR function ${ }^{16,26}$, and in our study, it was found decreased in PD-TOH compared to YHC (although not significantly). The lack of significant difference may be due to the way in which it is calculated (i.e., from the ratio between MBP recovery and its corresponding time $)^{26}$, inasmuch as this calculus takes into account both the magnitude ( $\mathrm{mmHg}$ ) and the duration (sec) of the recovery and, as in the case of SBP, the former did not significantly differ between groups (data not shown). Even PD-TOH patients have baroreflex abnormalities, albeit more subtle than those experienced by PD $+\mathrm{TOH}$ patients ${ }^{27}$. In our study, baroreceptor-HR reflex function was assessed using two different procedures. While it is true that BRS can be determined more easily than BRI in $\mathrm{PD}-\mathrm{TOH}$, its results were inconsistent with those obtained by BRI, since it did not detect blunted baroreceptor-HR reflex function.

Getting out of the bed is often difficult for PD patients ${ }^{28}$. This situation was patent when our patients assumed the upright posture from the supine and were comparatively slower than YHC. We also found that the bimodal pattern of the initial HR response to AS was entirely lost in all patients, this absence could be attributed to the aforesaid motor slowness ${ }^{2}$. For its part, $\mathrm{HR}_{\mathrm{c}}$ attenuation in $\mathrm{PD}-\mathrm{TOH}$ group might be explained by the age effect ${ }^{4}$.

In conclusion, the present study demonstrates that, in PD-TOH patients, there is a delay between the AS onset and SBP overshoot. This delay possibly reflects a prolonged latency in the baroreflex-mediated PVR response, but more studies are needed to confirm this preliminary hypothesis.

\section{References}

1. Wieling W, Krediet CT, van Dijk N, Linzer M, Tschakovsky ME. Initial orthostatic hypotension: review of a forgotten condition. Clin Sci (Lond) 2007;112:157-165.

2. Borst C, Wieling W, van Brederode JF, Hond A, de Rijk LG, Dunning AJ. Mechanisms of initial heart rate response to postural change. Am J Physiol 1982;243:676-681.

3. Borst C, van Brederode JF, Wieling W, van Montfrans GA, Dunning AJ. Mechanisms of initial blood pressure response to postural change. Clin Sci (Lond) 1984;67:321-327.

4. Wieling $W$, Veerman DP, Dambrink JH, Imholz BP. Disparities in circulatory adjustment to standing between young and elderly subjects explained by pulse contour analysis. Clin Sci (Lond) 1992;83:149-155.

5. Novak V, Novak P, Spies JM, Low PA. Autoregulation of cerebral blood flow in orthostatic hypotension. Stroke 1998;29:104-111.

6. Jamnadas-Khoda J, Koshy S, Mathias CJ, Muthane UB, Ragothaman M, Dodaballapur SK. Are current recommendations to diagnose orthostatic hypotension in Parkinson's disease satisfactory? Mov Disord 2009;24:1747-1751.
Niehaus L, Böckeler GC, Kupsch A, Meyer BU. Normal cerebral hemodynamic response to orthostasis in Parkinson's disease. Parkinsonism Relat Disord 2002;8:255-259.

8. Groothuis JT, Esselink RA, Seeger JP, van Aalst MJ, Hopman MT, Bloem BR. Lower vascular tone and larger plasma volume in Parkinson's disease with orthostatic hypotension. J Appl Physiol 2011;111:443-448.

9. Oka H, Toyoda C, Yogo M, Mochio S. Cardiovascular dysautonomia in de novo Parkinson's disease without orthostatic hypotension. Eur J Neurol 2011;18:286-292.

10. Goetz CG, Poewe W, Rascol O, et al. Movement Disorder Society Task Force report on the Hoehn and Yahr staging scale: status and recommendations. Mov Disord 2004;19:1020-1028.

11. Hughes AJ, Daniel SE, Kilford L, Lees AJ. Accuracy of clinical diagnosis of idiopathic Parkinson's disease: a clinico-pathological study of 100 cases. J Neurol Neurosurg Psychiatr 1992;55:181-184.

12. Lahrmann H, Cortelli P, Hilz M, Mathias CJ, Struhal W, Tassinari M. EFNS guidelines on the diagnosis and management of orthostatic hypotension. Eur J Neurol 2006;13:930-936. 
13. Freeman R, Wieling W, Axelrod FB, et al. Consensus statement on the definition of orthostatic hypotension, neurally mediated syncope and the postural tachycardia syndrome. Auton Neurosci 2011;161:46-48.

14. Guelen I, Westerhof BE, Van Der Sar GL, et al. Finometer, finger pressure measurements with the possibility to reconstruct brachial pressure. Blood Press Monit 2003;8:27-30.

15. Imholz BP, Settels JJ, van der Meiracker AH, Wesseling KH, Wieling W. Non-invasive continuous finger blood pressure measurement during orthostatic stress compared to intra-arterial pressure. Cardiovasc Res 1990;24:214-221.

16. Yamaguchi H, Tanaka H, Adachi K, Mino M. Beat-to-beat blood pressure and heart rate responses to active standing in Japanese children. Acta Paediatr 1996;85:577-583.

17. Wieling $\mathbf{W}$, Dambrink JH, Borst C. Cardiovascular effects of arising suddenly. N Engl J Med 1984;310:1189.

18. Gerhardt U, Schäfer M, Hohage H. Arterial blood pressure oscillation after active standing up in kidney transplant recipients. J Auton Nerv Syst 2000;80:93-100

19. Andersen EB, Boesen F. Sympathetic vasoconstrictor reflexes in Parkinson's disease with autonomic dysfunction. Clin Auton Res 1997;7:5-11.

20. Crandall CG, Shibasaki M, Yen TC. Evidence that the human cutaneous venoarteriolar response is not mediated by adrenergic mechanisms. J Physiol 2002;538:599-605.
21. Gniadecka M, Gniadecki R, Serup J, Søndergaard J. Impairment of the postural venoarteriolar reflex in aged individuals. Acta Derm Venereol 1994;74:194-196.

22. Henriksen 0. Sympathetic reflex control of blood flow in human peripheral tissues. Acta Physiol Scand 1991;603(Suppl):S33-S39.

23. Fusina S, Bongiovanni LG, Cacciatori V, Gemma L, Nardelli, Rizzuto N Venoarteriolar response in hemi Parkinson's disease. Auton Neurosci 2001;87:66.

24. Gulli G, Cooper VL, Claydon VE, Hainsworth R. Prolonged latency in the baroreflex mediated vascular resistance response in subjects with postural related syncope. Clin Auton Res 2005;15:207-212.

25. Fisher JP, Kim A, Young CN, et al. Influence of ageing on carotid baroreflex peak response latency in humans. J Physiol 2009;587:5427-5439.

26. Tanaka H, Thulesius O, Yamaguchi H, Mino M. Circulatory responses in children with unexplained syncope evaluated by continuous non-invasive finger blood pressure monitoring. Acta Paediatr 1994;83:754-761.

27. Jain S, Goldstein DS. Cardiovascular dysautonomia in Parkinson's disease: from pathophysiology to pathogenesis. Neurobiol Dis 2012;46:572-580.

28. Lees AJ, Blackburn NA, Campbell VL. The nighttime problems of Parkinson's disease. Clin Neuropharmacol 1988;11:512-519. 